\title{
Synthesis and Characterization of Vinyl Polymer-Grafted DNA and Its AB-Type Block Conjugate with Native DNA Fragment*
}

\author{
Daisuke UMENO, Masami KIJI, Masaharu MURATA, and Mizuo MAEDA ${ }^{\dagger}$ \\ Department of Materials Physics and Chemistry, Graduate School of Engineering, Kyushu University, \\ Hakozaki, Higashi-ku, Fukuoka 812-8581, Japan
}

(Received February 17, 1999)

\begin{abstract}
We have synthesized psoralen-terminated poly $(N$-isopropylacrylamide $)(1)$ and $\operatorname{poly}(N$-isopropylacrylamide-co$N, N$-dimethylacrylamide)(2), both of which show temperature-responsive properties and DNA-binding ability. These polymers were grafted on plasmid double stranded DNA through a photochemical reaction of their terminal psoralen groups. The double stranded DNA grafted with the vinyl polymers turned out to lose the function as templates for RNA synthesis, while it showed characteristic solution property derived from the vinyl polymers. Ligation reaction between the polymer-grafted DNA and native DNA resulted in the AB-type block conjugate with the polymer-grafted DNA as A-segment and native DNA as B-segment. It was found that the block conjugate which have two different functional domains retains two functions independently; B-domain of the block conjugate worked as a template for RNA synthesis, while A-domain responded to temperature and made the conjugate precipitate. In this way, one can construct tailor-made and precisely-regulated structures with multiple functions at his own will by using recombinant DNA techniques.

KEY WORDS DNA Conjugate / Psoralen / Poly $(N$-isopropylacrylamide) / Block Copolymer / Graft Copolymer / T4 DNA ligase / In Vitro Transcription /
\end{abstract}

Double stranded DNA (ds DNA) provides potent affinity functions for the sensing and purification of DNA-binding proteins $^{1,2}$ and DNA-binding drugs ${ }^{3,4}$. In fact, variety of ds DNA-comprising materials such as sepharose beads ${ }^{1,5}$, synthetic polymer resins ${ }^{2}$, polyacrylamide gels ${ }^{4}$, and silica gels ${ }^{6}$ have been developed and successfully utilized.

On the other hand, when one pays attention to the structural properties of DNA molecule, he would notice that DNA itself can provide a variety of functions which are never attained by the synthetic materials or chemicals ${ }^{7}$. For instance, ds DNA is interesting as a building block with highly-regulated one-dimensional structure. The size of the DNA strand can be precisely regulated at one's will by digestion (restriction endonucleases), elongation (polymerases), and ligation (DNA ligases), ranging oligomer to the gigantic chromosome having centimeter scale. All these factors let us imagine the possible use of DNA strands as molecular wires or as building blocks enabling various nano-scale architectures which are monodisperse, processible and even amplifiable. Molecules bearing ds DNA should provide a tool for constructing a new class of materials having novel structures and functions.

However, there have been reported very limited number of studies on this point of view. This is partly because there is no proper method for the chemical modification of ds DNA suitable for the utilization of the structural feature of ds DNA. This fact led us to develop a method for facile utilization of ds DNA as a building block.

Psoralen, which has been investigated as an antitumor agent $^{8}$, is a well known ds DNA specific binder. It has a photo-reactivity toward the pyrimidine bases on DNA: the reaction involves the formation of inter-strand cross-links in the DNA through the photocycloaddition of the 3,4- and $4 ', 5^{\prime}$-double bonds of the furocoumarin molecule ${ }^{9,10}$. We have demonstrated that psoralen derivatives were useful tools for the stable immobilization of ds DNA on silica

\footnotetext{
* This paper is dedicated to Professor Teiji Tsuruta in honor of his 80th birthday.

+ To whom correspondence should be addressed.
}

gels ${ }^{11}$.

Recently we have reported a method to graft vinyl polymers on ds DNA. The method relied on a vinyl monomer having a psoralen moiety which can form a photo adduct with DNA double-strands ${ }^{12,13}$. The 'psoralenmonomer' was photochemically immobilized on the ds DNA, then the resultant 'DNA-macromonomer' was copolymerized with acrylamide in aqueous system. The result was covalent grafting of polyacrylamide chains on ds DNA. The calf-thymus DNA grafted with $\operatorname{poly}(N$ isopropylacrylamide) (NIPAAm) was successfully applied to the separation of DNA-binding dyes ${ }^{14}$.

However, this approach contains several fundamental problems for the construction of the graft copolymer between DNA and vinyl polymers.

(1) There would remain a considerable amount of vinyl groups which had been photochemically immobilized on DNA strands but failed to participate in the subsequent polymerization reaction. This fact prevents us from preparing well-defined polymergrafted DNA.

(2) Polymer chain is introduced via random copolymerization between DNA macromonomer and vinyl monomer in a bulk. There would be a considerable distribution in the architecture of the graft chains, as well as in their molecular weight. This is not good for preparing conjugates with wellcharacterized and well-defined structures.

(3) The DNA-macromonomer itself may act as crosslinking agent because multiple vinyl groups are introduced on a DNA strand. Copolymerization might result in the formation of intermolecular or intramolecular network. It is not preferred for the preparation of the soluble conjugate.

As an alternative method, we recently developed much more facile method for the polymer grafting on ds DNA ${ }^{15}$. In the present study, polyNIPAAm and its copolymers with 
$N, N$-dimethylacrylamide (DMAAm) having a 4,5',8trimethylpsoralen (trioxalen) moiety on their terminus were synthesized. The polymers were photochemically grafted onto ds DNA, resulting in a functional DNA having temperature-responsive properties. The polymer-grafted DNA (A) was then connected with native DNA (B) with the aid of T4 DNA ligase to be the AB-type block conjugate. The resultant conjugate would be demonstrated to have two functions: temperature-responsiveness (derived from A block) and biological function (derived from B block).

\section{EXPERIMENTAL}

\section{Materials}

$N$-Isopropylacrylamide (NIPAAm) was obtained from Tokyo Kasei Kogyo and recrystallized from a mixture of benzene and hexane. $N, N$-Dimethylacrylamide (DMAAm), $N, N^{\prime}$-azobisisobutyronitrile (AIBN) and 3-mercaptopropionic acid (MPA) were purchased from Tokyo Kasei Kogyo, Kishida Chemicals and Aldrich, respectively. $N$-(3'Aminopropyl)- $N$-methyl-aminopropylaminomethyl-4,5',8trimethylpsoralen was synthesized according to the previous paper $^{13}$. Plasmid pBR322, pRL-CMV, and pBluescript SK(-) (pBS) were obtained from Fermentas, Promega, and RIKEN, respectively. T7 DNA polymerase was obtained from Stratagene. T4 DNA ligase, alkaline phosphatase, Hind III, EcoR I, BamH I, and Sty I were purchased from New England Biolabs. Inc. Other reagents and solvents were commercially obtained and used without further purification.

\section{Carboxyl-Terminated Copolymers of N-Isopropylacrylamide and $N, N$-Dimethylacrylamide}

Semitelechelic oligomer of NIPAAm was synthesized by the method described by Takei et al. ${ }^{16}$ Briefly, it was prepared by radical copolymerization of NIPAAm $(1.0 \mathrm{M})$ in dimethylformamide (DMF) with AIBN (2.0 mM) and MPA $(10 \mathrm{mM})$ as initiator and chain transfer agent, respectively. The polymers were purified by repeated reprecipitation from DMF-diethyl ether. Similarly, semitelechelic copolymers between NIPAAm and DMAAm was also synthesized by radical copolymerization of NIPAAm $(0.78 \mathrm{M})$ and DMAAm $(0.22 \mathrm{M})$ in DMF in the presence of AIBN $(2.0$ $\mathrm{mM})$ and MPA $(20 \mathrm{mM})^{17}$. The polymers were purified by repeated reprecipitation from DMF-diethyl ether. Molecular weight of the resulting polymers was determined both by acid-base titration of their terminus carboxyl group and by gel permeation chromatography (GPC).

In order to determine the phase transition temperature (lower critical solution temperature, LCST) of the polymers in aqueous solution, optical transmittance was monitored at $500 \mathrm{~nm}$ with temperature raised at the rate of $0.4{ }^{\circ} \mathrm{C} \mathrm{min} \mathrm{min}^{-1}$ using a spectrophotometer (Hitachi, U-3210). The temperature at $10 \%$ light transmittance of the polymer solutions was defined as the cloud point. Differential scanning calorimetric (DSC) measurements of aqueous solution of the polymers were also carried out with a SEIKO DSC-120 at a scanning rate of $0.5{ }^{\circ} \mathrm{C} \mathrm{min}$. . Composition of copolymers was determined by ${ }^{1} \mathrm{H}-\mathrm{NMR}$.

\section{Psoralen-Terminated Polymers}

The carboxyl group at terminus of the two polymers was esterified with $N$-hydroxysuccinimide by dicyclohexylcarbodiimide (DCC) in dry DMF at ca. $25{ }^{\circ} \mathrm{C}$ for $24 \mathrm{~h}$ in a molar ratio of $1.0: 1.2: 1.2$. The reaction mixture was concentrated in vacuo and was poured into diethyl ether to give a precipitate. The precipitate was dissolved again in the small portion of DMF, and poured into diethyl ether. The resultant white powder was dried in vacuo at room temperature. The activated polymers $(0.5 \mathrm{~g}$, $94 \mu \mathrm{mol})$ and $N$-(3'-aminopropyl)- $N$-methylaminopropylaminomethyl-4,5',8-trimethylpsoralen ${ }^{13}(0.07 \mathrm{~g}$, $235 \mu \mathrm{mol}$ ) were dissolved in dry DMF (total volume, $10 \mathrm{~mL}$ ). After stirring for $12 \mathrm{~h}$ at $c a .25^{\circ} \mathrm{C}$, the solution was concentrated in vacuo and was poured into diethyl ether. The precipitate was collected and washed with $100 \mathrm{~mL}$ of diethyl ether. The resultant white powder was dissolved in distilled water and dialyzed against $10 \mathrm{~L}$ of distilled water. The polymers thus obtained, psoralen-terminated polyNIPAAm (1) and psoralen-terminated poly(NIPAAmco-DMAAm) (2), were dissolved in pure water to be a stock solution whose concentration was determined from UV absorption due to the psoralen moiety $(300 \mathrm{~nm})$.
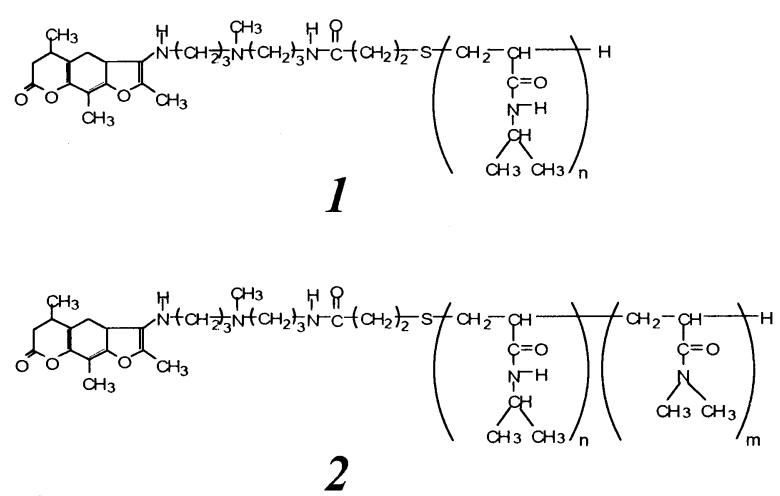

\section{Photoreaction between DNA and Psoralen-Terminated Polymers (1 and 2)}

A solution of pBR322 linearized with Sty I was mixed with each of the psoralen-terminated polymers. The final concentration of the DNA was $58 \mu \mathrm{M} \mathrm{bp}$, while that of the polymers was changed between 0 and $50 \mu \mathrm{M}$ in strand concentration. Each solution was irradiated (ca. 30 $\mathrm{mW} / \mathrm{cm}^{2}$ ) on an ice bath with a $500-\mathrm{W}$ ultra-high pressure $\mathrm{Hg}$ lamp equipped with a high-pass filter (Toshiba, UV-31) for $10 \mathrm{~min}$. The mixture was loaded on a $1.0 \%$-agarose gel, and the electrophoresis was performed at $7 \mathrm{~V} / \mathrm{cm}$ for $1 \mathrm{~h}$ in TAE buffer $(80 \mathrm{mM}$ Tris-acetate, $1 \mathrm{mM}$ EDTA, $\mathrm{pH}$ 7.6). Gel electrophoresis was performed at $10{ }^{\circ} \mathrm{C}$ since precipitation of polyNIPAAm takes place from aqueous glycerin $(25 \%)$ at ambient temperature ${ }^{18}$. After electrophoresis, DNA in the gel was stained by ethidium bromide.

Temperature-Induced Precipitation of Polymer-Grafted DNA

The resulting pBR322 grafted with polymers was examined from a view point of thermally-induced precipitation. To the grafted DNA solution $(100 \mu \mathrm{L}), 20$ $\mu \mathrm{L}$ of aqueous solution of polyNIPAAm $(10 \mathrm{w} / \mathrm{v} \%)$ was added $(1.7 \mathrm{w} / \mathrm{v} \%$ in total $)$. Then the mixture $(120 \mu \mathrm{L})$ was centrifuged $(15,000 \mathrm{rpm}, 3 \mathrm{~min})$ at $40^{\circ} \mathrm{C}$. After centrifugation, the supernatant was collected and subjected to gel electrophoresis $\left(0.7 \%\right.$ agarose, at $7 \mathrm{Vcm}^{-1}$ for $1 \mathrm{~h}$ in 
TBE). After the gel was stained by ethidium bromide, the DNA band was evaluated by scanning densitometry to estimate the degree of precipitation.

\section{Construction of Block Conjugate between Plasmid DNA and Polymer-Grafted DNA \\ Circular pBR322 DNA (4,363 bp) was digested with Hind} III (5'-A | AGCTT-3'), and then treated with alkaline phosphatase (Calf intestine, CIP), followed by heating $\left(65^{\circ} \mathrm{C}, 3 \mathrm{~min}\right)$, phenol extraction, and ethanol precipitation. The resultant DNA was dissolved in water and further treated with EcoR I (5'-G | AATTC-3') to give two linear ds DNA fragments $(4,332 \mathrm{bp}$ and $31 \mathrm{bp})$, both of which have two different terminus: a Hind III terminus without phosphate and an EcoR I terminus with 5'-phosphate. After the removal of the $31 \mathrm{bp}$-fragment using mol-cut device (Centricon-100, Amicon Inc.), the 4,332 bp-fragment was further purified by ethanol precipitation.

pBS $(2,961 \mathrm{bp})$ was treated similarly with Hind III and CIP, followed by the removal of the short DNA fragment. The resultant DNA, linear ds DNA (2,949 bp) having EcoR I and Hind III termini, was combined with 1 and irradiated with UV light as described above. The final concentrations of the pBS fragment and 1 at the photoreaction were $200 \mu$ $\mathrm{M} \mathrm{bp}$ and $200 \mu \mathrm{M}$ strand, respectively.

The 1-grafted pBS fragment was then mixed with the 4,332 bp-pBR322 fragment prepared above, followed by treatment with T4 DNA ligase (1200 units) at $13{ }^{\circ} \mathrm{C}$ for 47 $\mathrm{h}$. The solution conditions were as follows; the pBR 322 fragment, $23 \mathrm{nM}$ in strand; the 1-grafted pBS fragment, 23 $\mathrm{nM}$ in strand; $(50 \mathrm{mM}$ Tris- $\mathrm{HCl}, 10 \mathrm{mM} \mathrm{MgCl}, 10 \mathrm{mM}$ DTT, $1 \mathrm{mM}$ ATP, $50 \mu \mathrm{g} / \mathrm{mL}$ BSA, $\mathrm{pH}$ 7.8).

The ligation mixture was examined from a view point of thermally-induced precipitation. To the ligation mixture (185 $\mu \mathrm{L})$, aqueous solution of polyNIPAAm $(10 \mathrm{w} / \mathrm{v} \%)$ was added to be $1.5 \mathrm{w} / \mathrm{v} \%$. Then the mixture was centrifuged $(15,000 \mathrm{rpm}, 3 \mathrm{~min})$ at $40{ }^{\circ} \mathrm{C}$. Both of the supernatant and precipitate re-dissolved in the same volume of sterilized water were directly subjected to gel electrophoresis $(0.7 \%$ agarose, at $7 \mathrm{~V} / \mathrm{cm}$ for $1 \mathrm{~h}$ in TBE).

The precipitation fraction was then treated with EcoR I to disconnect pBR322 fragment from the block conjugate. The reaction mixture was subjected to gel electrophoresis and the band due to pBR322 was evaluated in order to estimate the degree of block conjugate formation.

\section{In Vitro Transcription of the Block Conjugate}

To plasmid pRL-CMV (4,079 bp) linearized with BamH I $(500 \mu \mathrm{M} \mathrm{bp})$ was reacted with $1(500 \mu \mathrm{M})$ as described above. The 1-grafted DNA was then devided to two vessels. One (200 $\mu \mathrm{M}$ bp) was mixed with the same amount of unmodified pRL-CMV (Bam $\mathrm{H}$ I digest) and T4 DNA ligase (1,200 units) and placed at $16{ }^{\circ} \mathrm{C}$ for $20 \mathrm{~h}$, while the other was diluted with TE buffer to make DNA concentration equal to each other. To the two solutions was added $1.0 \mathrm{w} / \mathrm{v} \%$ of polyNIPAAm and heated to $40{ }^{\circ} \mathrm{C}$. The precipitate fraction was extensively washed with water $\left(40{ }^{\circ} \mathrm{C}\right)$, dissolved in TE buffer, and stored at $4{ }^{\circ} \mathrm{C}$ for the following experiment

The TE solution of the precipitate fraction $(9.1 \mu \mathrm{L})$ was subjected to the in vitro transcription. The reaction conditions were as follows. T7 RNA polymerase, 20 units;
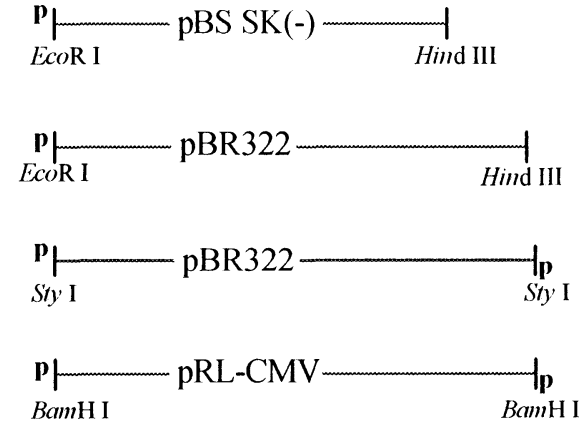

Figure 1. DNAs used in this study.

ribonucleotide triphosphates ( $\mathrm{rNTP}), 0.4 \mathrm{mM}$ each; $40 \mathrm{mM}$ Tris- $\mathrm{HCl}, 8 \mathrm{mM} \mathrm{MgCl}, 2 \mathrm{mM}$ spermidine, $50 \mathrm{mM} \mathrm{NaCl}$; $25{ }^{\circ} \mathrm{C}, 30 \mathrm{~min}$. The reactant was directly subjected to gel electrophoresis $\left(1.0 \mathrm{wt} \%\right.$ agar, $30 \mathrm{~min}$.) at $10^{\circ} \mathrm{C}$. The gel was stained by SYBR Gold (Molecular Probe).

\section{RESULTS AND DISCUSSION}

Psoralen-Terminated and Temperature-Responsive Polymers

PolyNIPAAm and poly(NIPAAm-co-DMAAm) having carboxyl terminus were synthesized by the method described by Takei et al. ${ }^{16,17}$ Number-averaged molecular weight $(\mathrm{Mn})$ of both polymers was determined to be $c a \cdot 14,000$ which corresponds to about 120 mer by titration of the terminal carboxyl groups. Mn was also estimated by GPC, which gave smaller value; 6,300 (ca. 55 mer) for polyNIPAAm, and 7,400 (ca. 65 mer) for poly(NIPAAm-coDMAAm). As for the copolymer, mole fraction of DMAAm was determined to be $22 \%$ by ${ }^{1} \mathrm{H}-\mathrm{NMR}$.

PolyNIPAAm is a well known polymer which shows a phase transition ${ }^{19}$ : when one gradually heats an aqueous solution of polyNIPAAm, it abruptly turns insoluble at $c a$. $31{ }^{\circ} \mathrm{C}$ and gives precipitates. As for homopolymer of NIPAAm, the transition temperature was found to be $31.2{ }^{\circ} \mathrm{C}$. On the other hand, that of a copolymer containing hydrophilic DMAAm was $40.9{ }^{\circ} \mathrm{C}$. This result well agrees with the previous report by others ${ }^{17}$.

The carboxyl end group of polymers was esterified according to the literature ${ }^{16}$. Subsequently, they were coupled with an amino derivative of psoralen ${ }^{15}$. The ratio of the polymer coupled with psoralen moiety was not very high $(18 \%$ for polyNIPAAm and $11 \%$ for poly(NIPAAmco-DMAAm)). This is probably due to unoptimized reaction conditions. However, the following experiments were carried out without further fractionation of the polymers.

\section{Polymer Grafting on Plasmid DNA}

Psoralens are known to intercalate into DNA double strands in dark and form covalent bonds at their 3,4 and 4', 5' double bonds with pyrimidines upon near-UV (365 $\mathrm{nm}$ ) irradiation $^{10}$. If the psoralen moiety introduced on the polymers reacts with the ds DNA, it would result in the covalent grafting of polymers on DNA.

As is seen in Figure 2a, there is observed significant retardation in DNA bands depending on the amount of 1 which had been fed before the photochemical reaction (lanes 3 - 9). This result should be ascribed to the fact that the surface charge density of DNA significantly decreased by 

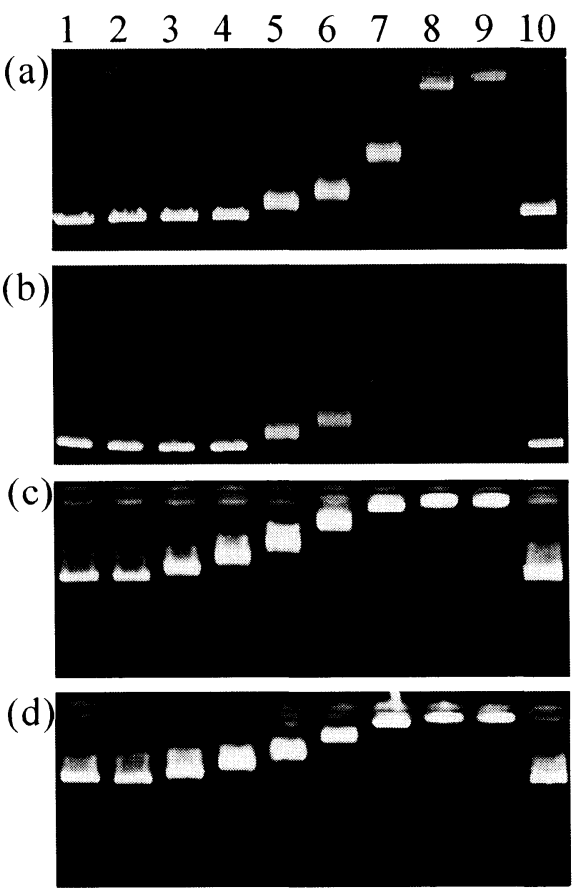

Figure 2. Gel electrophoresis of plasmid pBR322 grafted with 1 (a,b) and $2(\mathrm{c}, \mathrm{d})$. Plasmid pBR322 $(58 \mu \mathrm{M}$ bp) was mixed with the polymers $(0-50 \mu \mathrm{M}$ strand) and irradiated with UV light. Lane 1,

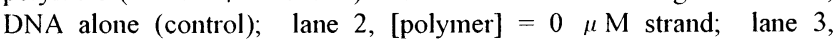
[polymer] $=0.2 \mu \mathrm{M} ; \quad$ lane 4 , [polymer] $=0.5 \mu \mathrm{M} ;$ lane 5, [polymer] $=1.0 \mu \mathrm{M} ;$ lane 6 , [polymer] $=2.0 \mu \mathrm{M} ;$ lane 7 , [polymer] $=5.0 \mu \mathrm{M} ; \quad$ lane 8, [polymer] $=20 \mu \mathrm{M} ; \quad$ lane 9, [polymer] $=50 \mu \mathrm{M} ;$ lane 10 , [polymer] $=50 \mu \mathrm{M}$, but was not irradiated with UV light. All the samples were then heated and centrifuged in the presence of $1.7 \mathrm{w} / \mathrm{v} \%$ of polyNIPAAm. The supernatant before (upper:(a)(c)) and after (lower:(b)(d)) centrifugation at $40{ }^{\circ} \mathrm{C}$ to be subjected to gel electrophoresis.

being jacketed with polymers. This was also the case for 2 (Figure 2c).

The gradual retardation that depends on the amount of the polymers (lanes 3 - 9 in Figure $2 \mathrm{a}$ and $2 \mathrm{c}$ ) indicates that one can regulate the degree of the modification with polymers by changing the amount of psoralen-terminated polymers used in the photoreaction.

Temperature-Induced Precipitation of Polymer-Grafted DNA

The resultant conjugates were examined from a view point of thermally-induced precipitation. Homopolymer of NIPAAm (1.7 wt \%) was added to the conjugate solutions because we found that a certain concentration $(>1.0 \mathrm{wt} \%)$ is required if one wants its precipitate reproducibly. The mixture was heated up to $40^{\circ} \mathrm{C}$ and centrifuged $(15,000$ $\mathrm{rpm})$ at the temperature. White precipitate was observed. The supernatant was carefully collected and subjected to gel electrophoresis.

In the case of pBR322 grafted with 1 (Figure 2b), the band intensity of the DNA drastically decreased with the increasing amount of $\mathbf{1}$ fed at the photochemical reaction, and at a certain level of polymer grafting (lanes 8 and 9), all the DNA disappeared from the supernatant. In contrast to this, the mixture of DNA and 1 showed no sign for such band fading (lane 10). These results indicate that DNA grafted with 1 has thermo-sensitive property and undergoes precipitation upon heating.

On the other hand, there was observed no change in the (a)

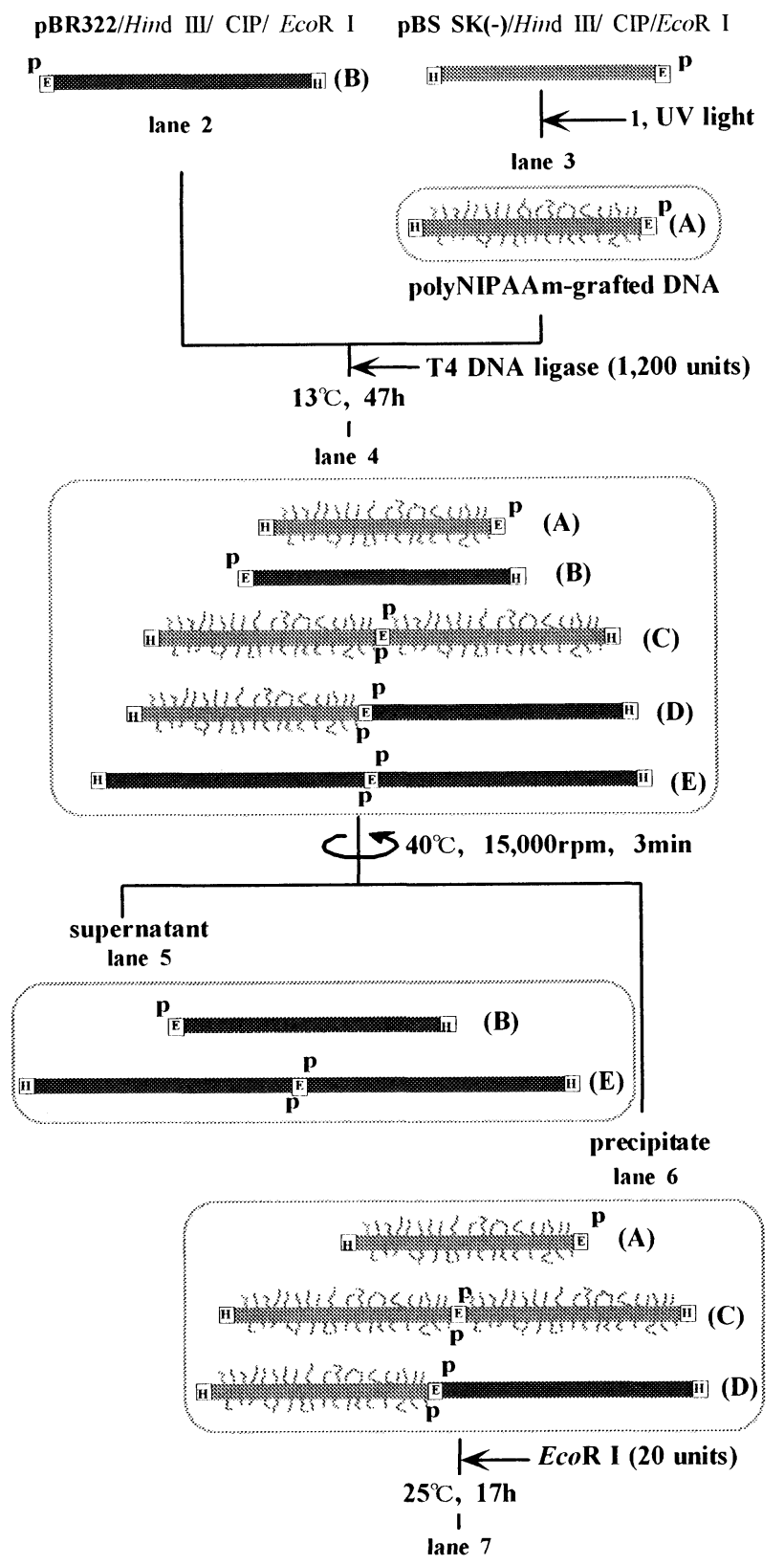

(b)

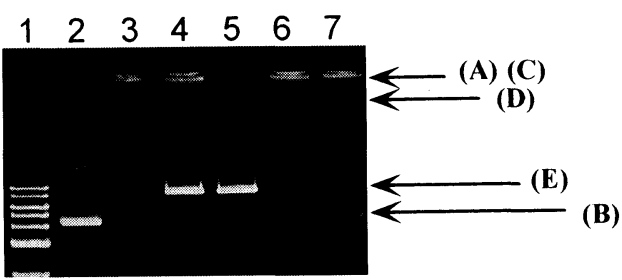

Figure 3. Preparation procedure (a) and gel electrophoresis (b) of $A B-$ type block copolymer between the pBR322 fragment and the 1-grafted pBS. Plasmid pBR322 was treated with Hind III, CIP, and EcoR I and the 4,332 bp-fragment was used as native ds DNA segment (lane 2). Plasmid pBS was treated similarly, and subjected to the photoreaction with 1 , resulting in the polymer-grafted ds DNA (lane 3 ). The two DNAs were mixed and treated with T4 DNA ligase (lane 4). The ligation mixture was then heated $\left(40^{\circ} \mathrm{C}\right)$ and centrifuged. Lane 5 , supernatant fraction. Lane 6 , precipitation fraction. The precipitation fraction was then treated with EcoR I to give pBR322 fragment disconnected from the AB-type block copolymer (lane 7). Lane 1 is a size maker. 
migration profile of pBR322 grafted with 2 between before (Figure 2c) and after (Figure $2 \mathrm{~d}$ ) the 'heat $\&$ centrifugation' procedure. This is because the transition temperature $\left(40.9^{\circ} \mathrm{C}\right)$ of the polymer is higher than temperature $\left(40{ }^{\circ} \mathrm{C}\right)$ to which the system heated in the present procedure.

Thus, the polymer-grafted DNA shows the solution properties strongly reflecting those of the grafting polymers.

\section{Block Conjugates between Native DNA and Polymer- Grafted DNA}

Ligation reaction between native pBR322 fragment with EcoR I and Hind III termini and the 1-grafted pBS fragment with EcoR I and Hind III termini was performed (Figure 3a). In this reaction, only the EcoR I terminus has a phosphate group, while the Hind III terminus was treated with phosphate (CIP) to eliminate the 5'-phosphate. Because T4 DNA ligase connects only the strands with 5'-phosphate group ${ }^{20}$, there should be three reactions in the system; one is the cross-coupling between the pBR322 fragment and 1grafted $\mathrm{pBS}$ fragment, and the other two are the dimerization (self-coupling) of the pBR322 fragments and that of the 1grafted $\mathrm{pBS}$ fragments.

The results are shown in Figure $3 \mathrm{~b}$. Lanes 2 and 3 show the pBR322 fragment $(4,332 \mathrm{bp})$ and 1-grafted pBS, respectively. Because of high molar ratio of 1 at the photoreaction, the grafted $\mathrm{pBS}$ showed no migration in the gel, remaining in the loading slot. When the mixture of the two components was treated with T4 DNA ligase, there appeared two new bands (lane 4). One is the sharp band due to the dimer $(8,664 \mathrm{bp})$ of the pBR322 fragment. The other was a broad and tardy band which is probably due to the block conjugate between the pBR322 fragment and the 1-grafted pBS. Subsequently, the ligation mixture was subjected to the 'heating \& centrifugation' procedure. Lanes 5 and 6 show the supernatant and precipitation fractions after the treatment, respectively. As is seen, the monomeric fragment $(4,332 \mathrm{bp})$ and its $\operatorname{dimer}(8,664 \mathrm{bp})$ were observed in the supernatant (lane 5), while the band of the 1-grafted pBS and the newly-appearing broad band were observed in the precipitation fraction (lane 6). This result further suggests that the broad band is that derived from the block conjugate. Interestingly, the block conjugate migrated faster than the 1-grafted $\mathrm{pBS}$, even though the size of the block conjugate should be much larger. It should be ascribed to the increase in its average charge/ surface ratio by attaching to the native DNA strand. It is well known that the surface charge density is one of the most important factors on the electrophoretic behavior of polyelectrolyte ${ }^{21}$.

The precipitation fraction (the sample for lane 6) was further treated with $E c o$ R I. The result is shown in lane 7 where appears the sharp band having the same mobility with pBR322. This clearly demonstrates that the precipitation fraction contained the block conjugate between the 1-grafted $\mathrm{pBS}$ and pBR322. From the band intensity, ca. 12\% of pBR322 originally fed in the ligation reaction was found to be incorporated in the block conjugate.

Thus, although the yield of cross-coupling reaction was rather low in the present conditions, the AB-type block conjugate between native ds DNA and 1-grafted ds DNA was obtained by the ligation reaction, and the resultant conjugate was proved to undergo temperature-directed precipitation.

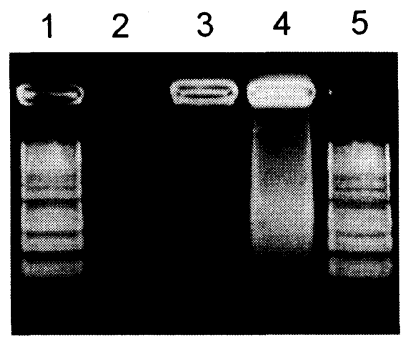

Figure 4. In Vitro transcription of 1-grafted pRL-CMV and block conjugate between 1-grafted pRL-CMV and native pRL-CMV. The blank solution without template (TE, lane 2), 1-grafted pRL-CMV (lane 3 ), and block conjugate (lane 4) were treated with T7 RNA polymerase in the presence of $\mathrm{rNTP}(0.4 \mathrm{mM}$ each $)$ at $25^{\circ} \mathrm{C}$ for $30 \mathrm{~min}$. The reaction products were subjected to gel electrophoresis ( $1 \%$ agar, $30 \mathrm{~min}$.) at $10^{\circ} \mathrm{C}$ and stained with SYBER Gold. Lane 1 and 5 are ds DNA size maker ( $1 \mathrm{~kb}$ ladder, New England Biolab.)

\section{In Vitro Transcription of the DNA Connected with Polymer- Grafted DNA}

In order to ascertain the template function of the native DNA connected to the polymer-grafted DNA, the block conjugate between the 1-grafted pRL-CMV and native $\mathrm{pRL}$ $\mathrm{CMV}$ was subjected to the in vitro transcription. To eliminate the transcription from intact DNA contaminated, the conjugate sample was subjected to 'heat and centrifugation' process repeatedly and the temperatureresponsive fraction was used for the subsequent transcription reaction.

The result is shown in Figure 4. It is assumed that DNA should dramatically change its function as genetic information upon polymer grafting because the grafting method in this paper relies on photoreaction which results in irreversible photocrosslinking of its double strand. As expected, 1-grafted pRL-CMV did not give any transcription product after the polymerase reaction. On the other hand, block conjugate gives intensive broad band which is ascribed to the newly synthesized single stranded RNA. This result apparently indicates that DNA which is connected to the polymer-grafted DNA is capable of serving as templates for RNA synthesis. Thus the block conjugate between 1grafted pRL-CMV and native pRL-CMV turned out to have two functions at a time; the function to give a transcription product (owing to native DNA block) and the function to precipitate in response to temperature change (owing to 1 grafted DNA block).

\section{CONCLUDING REMARKS}

We have synthesized temperature-sensitive polymers with psoralen terminus. Each polymer showed its characteristic transition temperature and precipitated when heated over the temperature. In addition, all the polymers turned out to bind covalently to ds DNA upon UV irradiation. The photoreaction resulted in ds DNA grafted with polymers. The change in migration rate of polymer-grafted DNA in the gel electrophoresis was found to be dependent on the degree of polymer modification, which can be controlled by the feed ratio at the photoreaction.

Plasmid DNA grafted with 1 did not give any transcription product probably due to structural alternation by the polymer grafting. In turn, it showed characteristic solution properties derived from the grafting polymer: when heated and centrifuged at $40{ }^{\circ} \mathrm{C}$, plasmid DNA grafted with 1 (Tc < $40{ }^{\circ} \mathrm{C}$ ) precipitated, while plasmid DNA grafted with 2 (Tc $>$ 
$\left.40{ }^{\circ} \mathrm{C}\right)$ remained in the supernatant. The results indicate that one can prepare functional domains having preciselyregulated size and functions by this methods.

Ligation reaction between the polymer-grafted DNA (A) and native DNA (B) resulted in the AB-type block copolymers between them. It was clearly shown that the block conjugate, having two different functional domains, retains two functions independently; B-domain of the block conjugate worked as a template for RNA synthesis, while Adomain responded to the temperature and made the conjugate precipitate. Therefore, we assume that the block conjugate should serve as separation reagent for sequence specific DNA-binding proteins: B-domain captures a protein of one's interest, while $\mathrm{A}$ domain makes the protein precipitate together with the block conjugate. Further works in these directions are currently under way.

Using the present method, one can construct tailor-made and precisely-regulated structures with multiple functions. The basis of this method can be regarded as a coupling reaction between two terminal groups of different polymers. Because the coupling reaction is catalyzed by the enzyme (T4 DNA ligase), the reaction is very selective in nature. Though this paper only describes the tandem connection of two functional cassettes (native DNA and DNA grafted with temperature-responsive polymer), this strategy would enable us to construct much more complex structures.

Acknowledgment. This work was supported by a Grantin-Aid for Scientific Research on Priority Areas, "New Polymers and Their Nano-Organized Systems" (No. 277 / 10126244), from The Ministry of Education, Science, Sports and Culture of Japan.

\section{REFERENCES}

1. J.T. Kadonaga, Methods Enzymol., 208, 10 (1991).

2. H. Kawaguchi, $\Lambda$. Asai, Y. Ohtsuka, H. Watanabe, T. Wada, and H. Handa, Nucleic Acids Res., 17, 6229 (1989).

3. A. Inagaki and M. Kageyama, J. Biochem., 68, 187 (1970).

4. D. Umeno, T. Kano, and M. Maeda, Anal. Chim. Acta., 365, 101 (1998).

5. J.T. Kadonaga and R. Tjian, Proc. Natl. Acad. Sci. USA, 83, 5889 (1986).

6. H.W. Jarrett, J. Chromatogr., 618, 315 (1993).

7. D. Umeno and M. Maeda, Kobunshi, 46, 314 (1997).

8. B.R. Scott, M.A. Pathak, and G.R. Molnn, Mutat. Res., 39, 29 (1976).

9. P.-S. Song and K.J. Tapley, Jr., Photochem. Photobiol., 29, 1177 (1979).

10. G.D. Cimino, H.B. Gamper, S.T. Isaacs, and J. E. Hearst, Ann. Rev. Biochem., 54, 1151 (1985).

11. S. Kashiwagi, K. Ohmori, M. Maeda, and M. Takagi, Anal. Sci., 8, 261 (1992)

12. M. Maeda, C. Nishimura, D. Umeno, and M. Takagi, Bioconjugate (hem., 5, 527 (1994)

13. M. Maeda, D. Umeno, C. Nishimura, and M. Takagi, in "Hydrogels and Biodegradable Polymers for Bioapplications," R.M. Ottenbrite, S.J. Huang, and K. Park, Ed., American Chemical Society, Washington D.C., 1996, p197.

14. D. Umeno and M. Maeda, Anal. Sci., 13, 553 (1997).

15. D. Umeno, M. Kawasaki, and M. Maeda, Bioconjugate Chem., 9, 719 (1998)

16. Y.G. Takei, T. Aoki, K. Sanui, N. Ogata, T. Okano, and Y. Sakurai, Bioconjugate Chem., 4, 42 (1993).

17. Y.G. Takei, T. Aoki, K. Sanui, N. Ogata, T. Okano, and Y. Sakurai, Bioconjugate Chem., 4, 341 (1993).

18. M. Maeda, C. Nishimura, A. Inenaga, and M. Takagi, Reactive Polym., 21, 27 (1993).

19. H.G. Schild, Prog. Polym. Sci, 17, 163 (1992).

20. J. Sambrook, E.F. Fritsch, and T. Maniatis, in "Molecular Cloning," 2nd ed., Cold Spring Harbor Laboratory Press, Cold Spring Harbor, NY., 1989, pl.

21. O.J. Shaw, "Electrophoresis," Academic Press, London, 1969 